\title{
How an Elite High-performance Weightlifter with Spine Pain Became a Silver and Gold Olympic Winner: A Case Report
}

\author{
Jorge Felipe Ramirez, MD, Jose Gabriel Rugeles Ortiz, MD, Carolina Ramirez Martinez, MD, \\ Enrique Osorio Fonseca, MD, Nicolas Prada Ramirez, MD, and Gabriel Oswaldo Alonso Cuellar, DVM, MSc
}

Spine pain affects athletes' performance and is a common reason for missed playing time. Return-to-play is the main concern for patients; for this reason, treatment must be evaluated under these criteria. Nonsurgical treatment and specific physical rehabilitation should be the first option. There are few reports using endoscopic spine surgery in high-performance weightlifters. We report a successful case of a 33-year-old elite high-performance weightlifter with cervical and lumbar intervertebral disc hernias, who, after anterior cervical endoscopic discectom in 2009 and then a transforaminal lumbar endoscopic discetomy and percutaneous interspinours space in 2014, won silver and gold Olympic medals, set an Olympic record, and won a weightlifting world championship after. We concluded that return-to-play after 2 endoscopic spine surgeries was possible for a high-performance weightlifter. Endoscopic spine surgery is an alternative to treat spine pain in elite high-performance athletes.

Key words: Intervertebral disc hernia, weightlifter, endoscopic spine surgery, gold medal, silver medal, Olympic games, case report.
Cervical and lumbar pain are important causes of disability (1). Among elite athletes, approximately $30 \%$ will have at least one episode of acute low back pain during their career (2). Spinal pain affects the performance of athletes and is a common reason for missed playing time (3). Among elite weightlifters, the spine is one of the most common areas with injuries $(4,5)$. A recent study reported that $52 \%$ of athletes who received spine magnetic resonance imaging (MRI) after the 2016 Olympic Games in Rio de Janeiro, Brazil showed moderate to severe spinal disease, with weightlifting representing the second highest sport-specific incidence of spine disease (6).

Nonsurgical treatment and specific physical reha-

From : Reina Sofía Clinic \& Center of Minimally Invasive Spine Surgery, Bogotá, D.C., Colombia

Author for correspondence: Jorge Felipe Ramirez, MD

Address: Centro de Columna-Cirugia Minima Invasiva, Cra 45 N 10476,CP 110111, Bogota, Colombia

E-mail: jframirezl@yahoo.com bilitation provide symptom relief in a high percentage of athletes affected by intervertebral disc herniation (IDH) $(7,8)$. For cases in which conservative management fails, besides conventional open surgery, endoscopic spine surgery (ESS) is an option (9). However, there have been no previous reports of endoscopic treatment of cervical and lumbar IDH involving an elite high-performance weightlifter. We report the case of an elite high-performance weightlifter who, after being treated for cervical and lumbar IDH with ESS, won silver and gold Olympic medals, set an Olympic record, and won a World Championship.

\section{CASE REPORT}

\section{Cervical Spine Surgery}

A33-year-old man who is an elite high-performance weightlifter participated in the Beijing Olympics in 2008 resulting in wrist-arm pain. The patient presented to us in 2009 with a 2-year history of radiated right arm pain. He was diagnosed with a C6-7 IDH. An x-ray showed no instability (Fig. 1). He reiterated his strong wish to return to competition in the 2012 London Olympics. He underwent an anterior cervi- 
cal endoscopic spine surgery in early 2009. Under local anesthesia and sedation, we performed a fullendoscopic discectomy in C6-7 (Fig. 2). The patient was discharged the same day. Magnetic resonance imaging (MRI) performed at 4 weeks post surgery showed a complete disc decompression; he then started his normal training. He began participating in

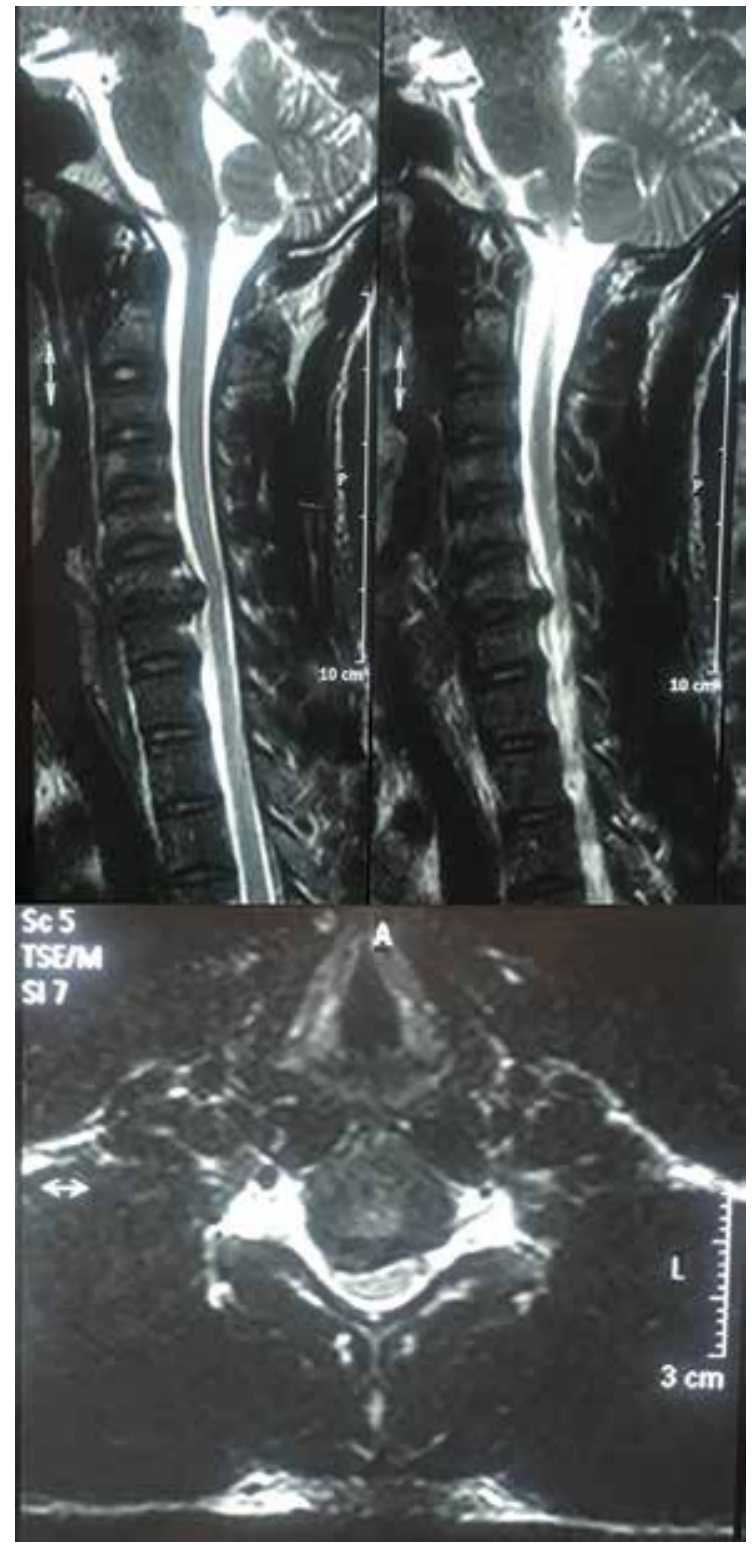

Fig. 1. T2 sequence of cervical magnetic resonance imaging (MRI) revealed the presence of intervertebral disc herniation (IDH) at C6-7 level. competitions at 10 months post surgery in regional games. At 40 months from surgery, he participated in the 2012 London Olympics and won the silver medal and he set an Olympic record for the "clean \& jerk" in the 62-kg category with $177 \mathrm{~kg}(10)$. At 48 months follow-up, MRI showed complete decompression resulting in a relief of arm pain (Fig. 3).

\section{Lumbar Spine Surgery}

Then, in later 2015, the patient returned with lumbar pain radiating to his left buttock and was diagnosed with a L4-5 and L5-S1 IDH (Fig. 4). We decided to perform a transforaminal endoscopic spine discectomy on L4-5, a percutaneous discectomy on L5-S1, and a percutaneous interspinous spacer on L4-5 (Fig. 5). Three months following the procedure, he started to train normally; 7 months after surgery, the patient competed in the 2016 Rio Olympics and won the gold medal (Fig. 6). Follow-up at 2 years showed a correct position of the implant and pain relief.

\section{DISCUSSION}

Weightlifting is a strength sport that may produce the greatest power outputs of any human activity (4). This sport consists of 2 exercises: the clean and jerk and the snatch, in which the lifter must lift maximal loads for one repetition (5). The risk of injury during heavy lifting is a well-recognized problem (11). Nevertheless, weightlifting has a relatively low incidence of injuries compared with other sports $(5,12)$. A recent study showed that only $20 \%$ of weightlifters' injuries were classified as severe, just $25 \%$ were chronic, and more than $80 \%$ of patients obtained symptom relief 4 weeks after injury (13); incidence ranged between 2.4 and 3.3 injuries per 1000 hours of training $(14,15)$.

Neck pain and low back pain related to sports are spine injuries that can cause abstinence from competition and substantially affect athletes' professional life (13). Because of its exercises, weightlifting implies a high load on the spine. Cholewicki et al (16) reported average compressive loads on L4-L5 up to 17,192 $\mathrm{N}$ during an elite weightlifters' training session. This progressive, cumulative, and repetitive stress can lead to the development of degenerative changes resulting in an IDH (12). Reports of spine injuries in weightlifting vary from $1 \%$ to $59 \%$ (5). Interestingly, Jonasson et al (17) report a relationship between 


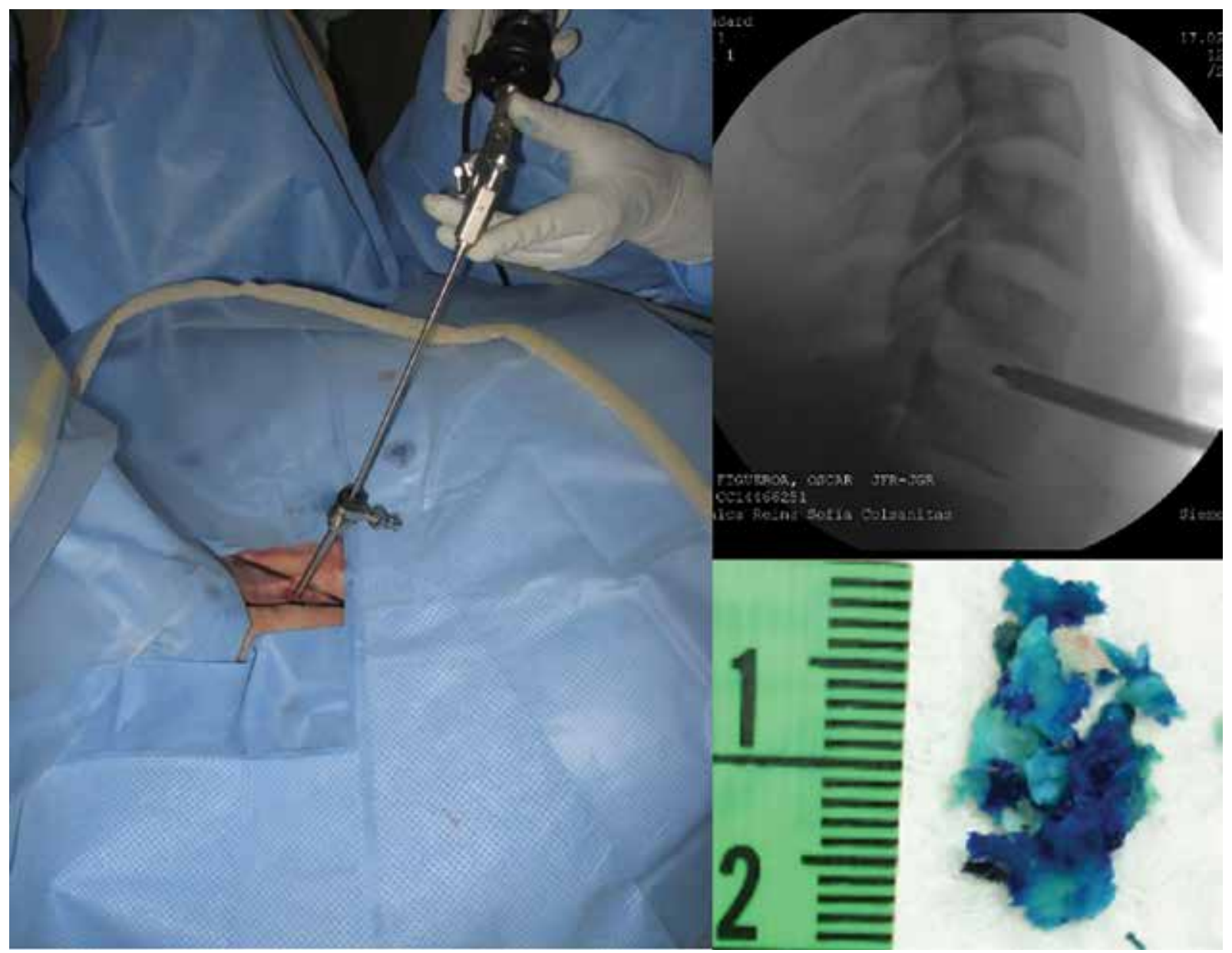

Fig. 2. Anterior cervical endoscopic spine discectomy at C6-7 level for IDH.

spine pain and shoulder, hip, and knee pain. These factors could increase the likelihood of abstinence from competition. In our patient, there were no concomitant joint injuries, probably a factor that improved his outcome.

Return-to-play is the main concern for patients, and is probably the first, or at least the most important, request from them; therefore, it is critical for the surgeon to base this decision on reproducible metrics (18). According to Huang et al (19), after a sports-related spine injury or a surgical spine procedure, an athlete should be neurologically intact, be pain-free, be at full strength, and have full range of motion before returning to competitive athletic activities; for this reason, treatment must be evaluated under these criteria. The first treatment option should always be a conservative therapy with pain killers, injections, and physical therapy. In some cases where this support is not successful, the next step could be surgery depending on the type of injury (18). For cervical $\mathrm{IDH}$, the most accepted surgical treatment is anterior cervical discectomy and fusion (ACDF). A systematic review reported that for athletes who underwent ACDF for IDH, the return-to-play rates are between $56.2 \%$ and $86.7 \%$; nevertheless, the impact on the performance score after cervical surgery remains unclear (16). That review only included team sports. Regarding lumbar IDH, the gold standard treatment is open discectomy. Nair et al (17) found that $75 \%$ to 


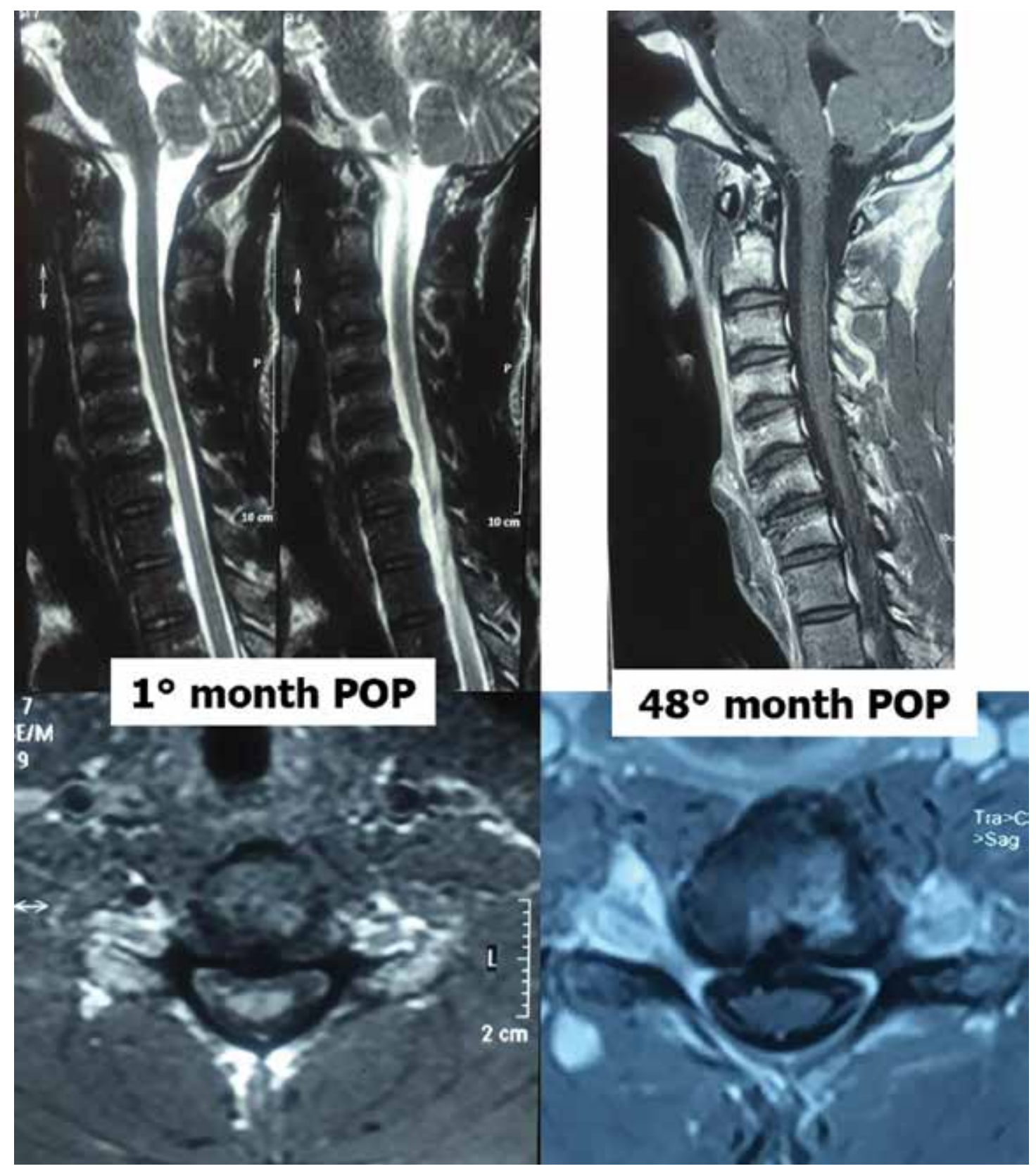

Fig. 3. Postoperative MRI showing complete decompression of cervical IDH.

$100 \%$ of elite athletes returned to play after surgery and reached an average of $64.4 \%$ to $103.6 \%$ of performance. However, in these studies, there was not a weightlifting Olympic champion.
Regarding endoscopic spine surgery treatment, Sairyo et al (7) reported 4 cases of professional athletes treated with percutaneous endoscopic lumbar surgery, all of whom returned to play at the same level as their original performance and without pain. 


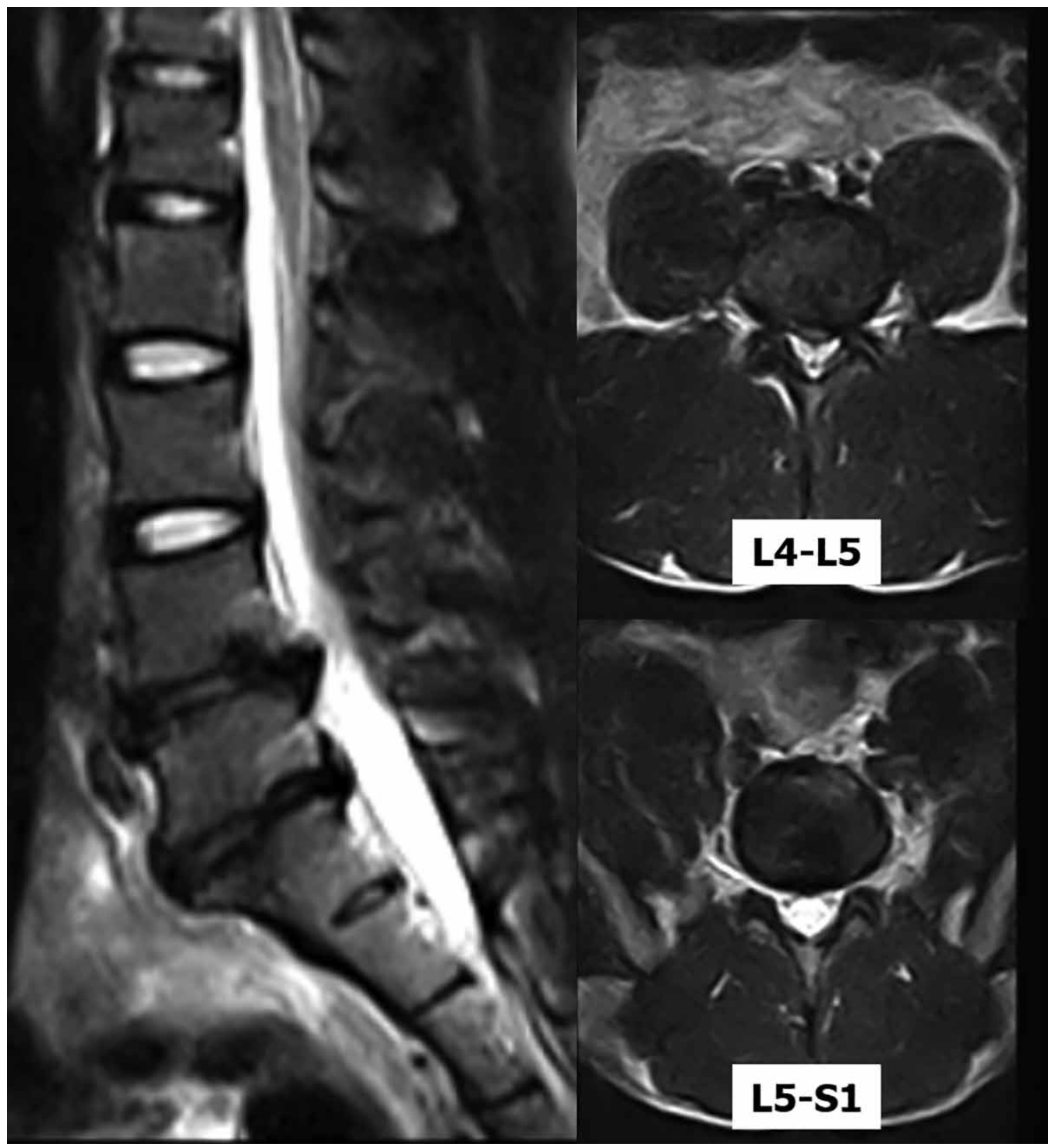

Fig. 4. T2 sequence of lumbar MRI revealed the presence of discal pathologies at L4-5 and L5-S1 levels.

We concluded that ESS could be an excellent alternative to treat secondary pain associated with IDH in elite high-performance weightlifters. All patients must be evaluated according to the injury and sport, and with the aim to reach an effective return to play.

\section{Compliance with Ethical Standards}

Written consent was obtained from the patient to publish this case. 


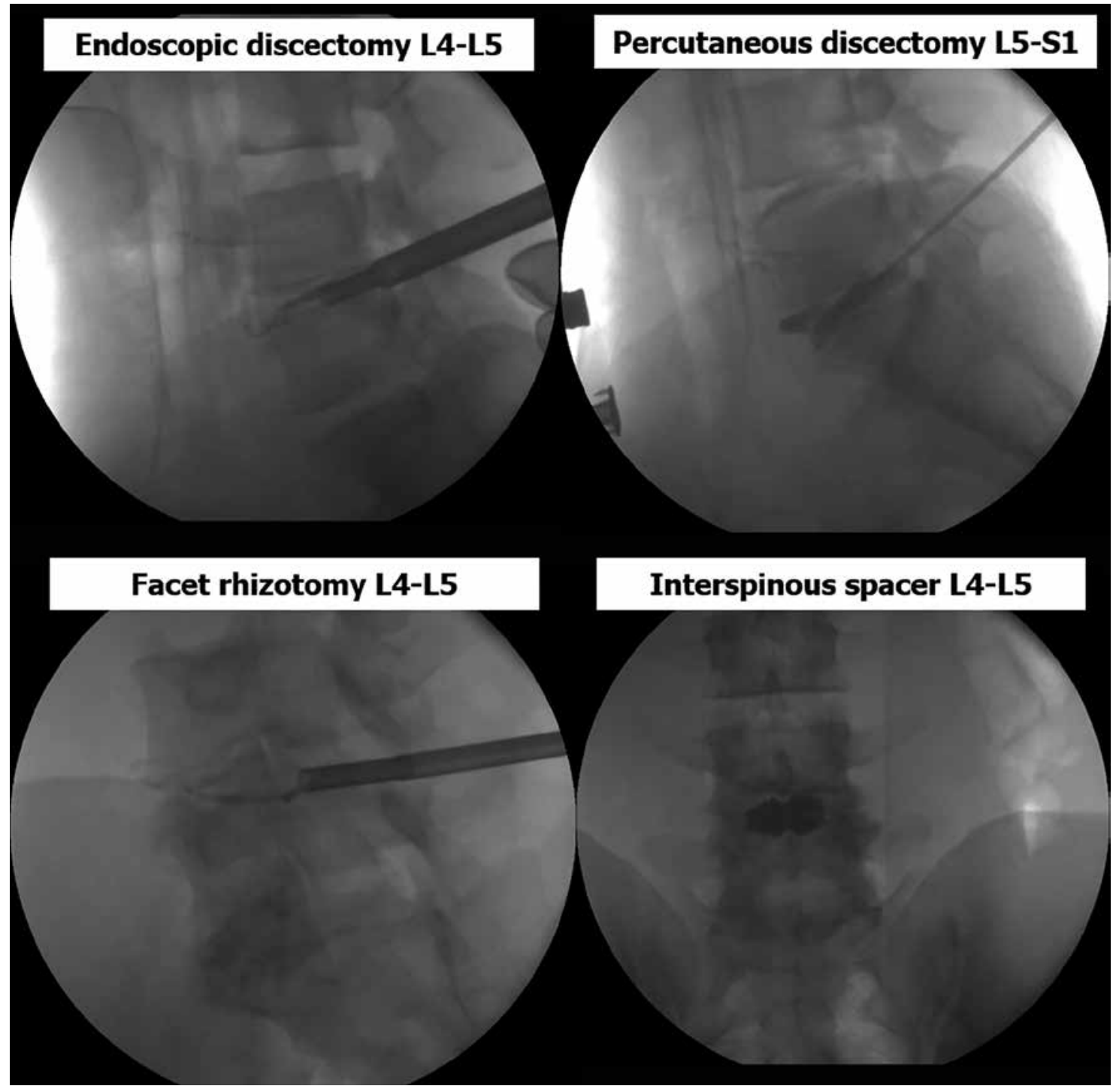

Fig. 5. Minimally invasive spine procedures at L4-5 and L5-S1 levels. 

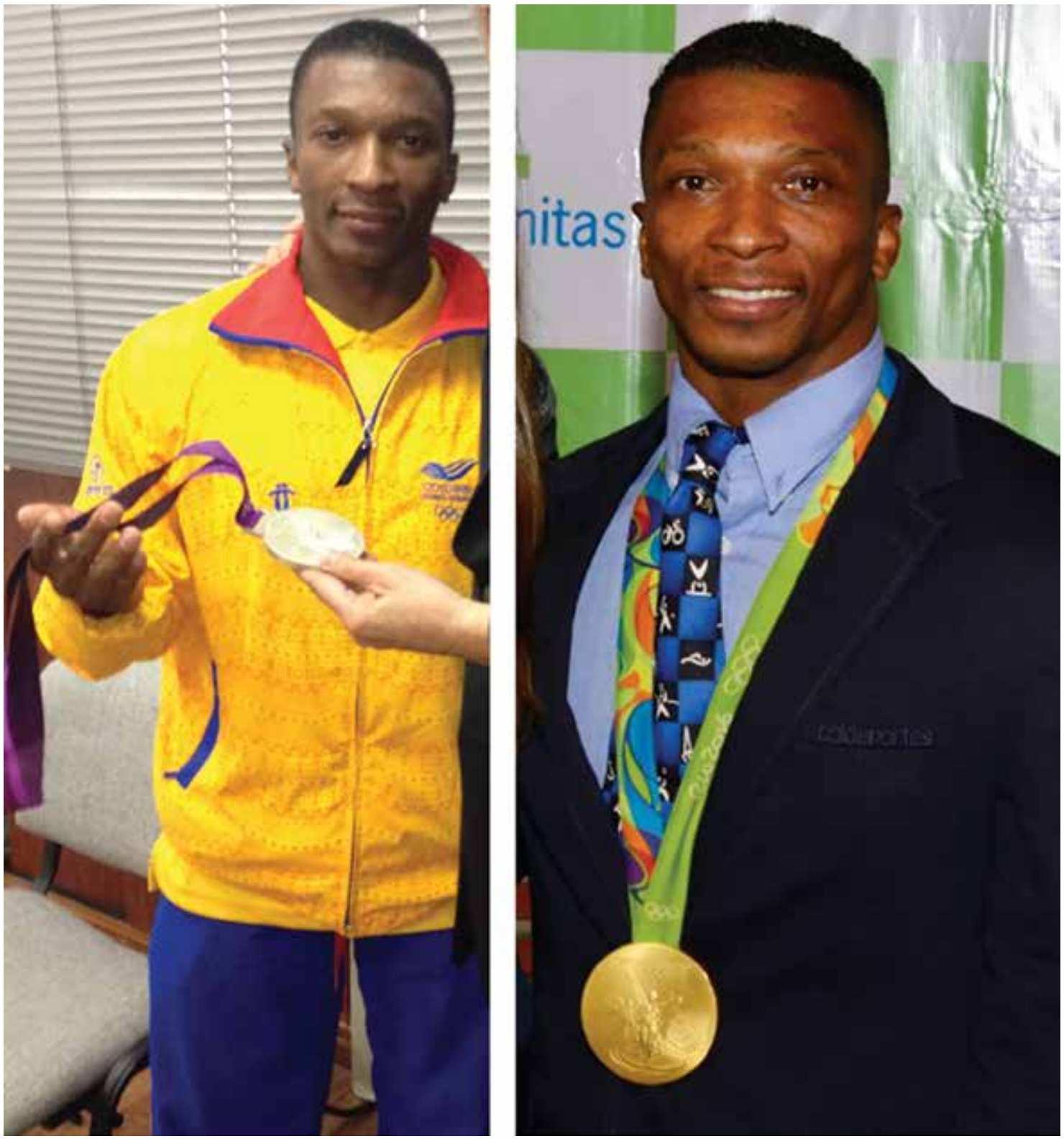

Fig. 6. Weightlifter with his silver and gold medals. 


\section{REFERENCES}

1. Kerr D, Zhao W, Lurie JD. What are long-term predictors of outcomes for lumbar disc herniation? A randomized and observational study. Clin Orthop Relat Res 2015; 473:1920-1930.

2. Akshay G, Kunal S, Abhay N. Outcomes of various treatment modalities for lumbar spinal ailments in elite athletes: A literature review. Asian Spine ] 2018; 12:754-764.

3. Cook RW, Hsu WK. Return to play after lumbar spine surgery [published online ahead of print June 9, 2016]. Clin Sports Med 2016; 35:609-619.

4. Keogh JW, Winwood PW. The epidemiology of injuries across the weight-training sports. Sports Med 2017; 47:479-501.

5. Aasa U, Svartholm I, Andersson F, Berglund L. Injuries among weightlifters and powerlifters: A systematic review. Br J Sports Med 2017; 51:211-219.

6. Wasserman MS, Guermazi A, Jarraya M, Engbretsen L, Abdalkader M, Roemer FW, Hayashi D, Crema MD, Mian AZ. Evaluation of spine MRIs in athletes participating in the Rio de Janeiro 2016 Summer Olympic Games. BMJ Open Sport Exerc Med 2018; 4:e000335.

7. Alvi MA, Kerezoudis P, Wahood W, Goyal A, Bydon M. Operative approaches for lumbar disc herniation: A systematic review and multiple treatment meta-analysis of conventional and minimally invasive surgeries. World Neurosurg 2018; 114:391-407.

8. Hsu WK, Jenkins TJ. Management of lumbar conditions in the elite athlete. J Am Acad Orthop Surg 2017; 25:489-498.

9. Sairyo K, Kitagawa Y, Dezawa A. Percutaneous endoscopic discectomy and thermal annuloplasty for professional athletes. Asian J Endosc Surg 2013; 6:292-297.

10. IWF - International Weightlifting Federation. Men's Olympic Records. 2018. www.iwf.net/results/olympic-records/. Date Accessed 08/06/2018.

11. Hoogendoorn WE, van Poppel MN, Bongers PM, Koes BW, Bouter LM. Physical load during work and leisure time as risk factors for back pain. Scand J Work Environ Health 1999; 25:387403.
12. Engebretsen L, Soligard T, Steffen K, Alonso JM, Aubry M, Budgett R, Dvorak J, Jegathesan M, Meeuwisse WH, Mountjoy M, Palmer-Green D, Vanhegan I, Renström PA. Sports injuries and illnesses during the London Summer Olympic Games 2012. Br] Sports Med 2013; 47:407-414.

13. Naghdi S, Nakhostin Ansari N, ShamsSalehi S, Feise RJ, Entezary $\mathrm{E}$. Validation of the functional rating index for the assessment of athletes with neck pain. World J Orthop 2016; 7:507-512.

14. Calhoon G, Fry AC. Injury rates and profiles of elite competitive weightlifters. J Athl Train 1999; 34:232-238.

15. Raske A, Norlin R. Injury incidence and prevalence among elite weight and power lifters. Am J Sports Med 2002; 30:248-256.

16. Cholewicki J, McGill SM, Norman RW. Lumbar spine loads during the lifting of extremely heavy weights. Med Sci Sports Exerc 1991; 23:1179-1186.

17. Kadow T, Sowa G, Vo N, Kang JD. Molecular basis of intervertebral disc degeneration and herniations: What are the important translational questions? Clin Orthop Relat Res 2015; 473:19031912.

18. Jonasson $\mathrm{P}$, Halldin $\mathrm{K}$, Karlsson J, Thoreson O, Hvannberg J, Swärd L, Baranto A. Prevalence of joint-related pain in the extremities and spine in five groups of top athletes. Knee Surg Sports Traumatol Arthrosc 2011; 19:1540-1546.

19. Rosenthal BD, Boody BS, Hsu WK. Return to play for athletes. Neurosurg Clin N Am 2017; 28:163-171.

20. Huang P, Anissipour A, McGee W, Lemak L. Return-to-play recommendations after cervical, thoracic, and lumbar spine injuries: A comprehensive review. Sports Health 2016; 8:19-25.

21. Joaquim AF, Hsu WK, Patel AA. Cervical spine surgery in professional athletes: A systematic review. Neurosurg Focus 2016; 40:E10.

22. Nair R, Kahlenberg CA, Hsu WK. Outcomes of lumbar discectomy in elite athletes: The need for high-level evidence. Clin Orthop Relat Res 2015; 473:1971-1977. 